\title{
ANALISIS PEMODELAN DATA PASANG SURUT MENGGUNAKAN MODEL TPXO 7.1 DI PELABUHAN TANJUNG PRIOK, JAKARTA UTARA
}

\section{ANALYSIS OF TIDAL MODEL USING TPXO 7.1 MODEL IN THE PORT OF TANJUNG PRIOK, NORTH JAKARTA}

\author{
Septi Hermialingga ${ }^{1}$, Anna IS Purwiyanto ${ }^{1}$, \& Iskhaq Iskandar ${ }^{2}$ \\ ${ }^{1}$ Program Studi Ilmu Kelautan, Fakultas MIPA, Universitas Sriwijaya \\ ${ }^{2}$ Program Studi Fisika, Fakultas MIPA, Universitas Sriwijaya \\ Jl. Raya Palembang - Prabumulih Km. 32 Indralaya, Ogan Ilir, Sumatera Selatan. Telepon/Faks : (0711) 580069 \\ e-mail : shermialingga@gmail.com
}

Diterima tanggal: 18 Maret 2019 ; diterima setelah perbaikan: 26 Agustus 2020; Disetujui tanggal: 27 Agustus 2020

\begin{abstract}
ABSTRAK
Aktifitas pembangunan dan pelayaran di Pelabuhan Tanjung Priok sangat tinggi sehingga membutuhkan informasi pasang surut guna mendukung perencanaan pembangunan, alur keluar masuk kapal untuk bongkar muat barang, serta keselamatan pelayaran. Oleh karena itu, penelitian ini bertujuan untuk membandingkan karakteristik pasang surut observasi dengan karakteristik pasang surut prediksi model TPXO 7.1 dari perangkat lunak Tidal Model Driver (TMD) serta menganalisa keakurasian data pasang surut model TPXO 7.1. Metode penelitian yang digunakan untuk mengolah data observasi pasang surut menggunakan metode admiralty dan data prediksi pasang surut didapat dari model TPXO 7,1. Validasi data pasang surut dilakukan dengan menghitung Root Mean Square Error (RMSE) dan korelasi dari kedua data. Penelitian ini dilaksanakan bulan Maret 2018. Hasil analisis menunjukkan bahwa tipe pasang surut dari data prediksi model TPXO 7.1 dan data pengamatan langsung memiliki tipe pasang surut campuran dominan ke tunggal. Akurasi data pasang surut model TPXO 7.1 memiliki nilai RMSE sebesar 0,14 dan korelasi sebesar 0,73, dengan demikian data prediksi Model TPXO 7.1 dapat digunakan untuk menggantikan data observasi pada wilayah yang tidak diukur langsung.
\end{abstract}

Kata kunci: Pasang surut, Model TPXO 7.1, prediksi pasut, tipe pasut.

\section{ABSTRACT}

The development and shipping activities in the Port of Tanjung Priok are very high and require tidal information. Therefore, this research aimed to compare the tidal characteristics of observations with the predicted tides of the TPXO 7.1 model product from the Tide Model Driver (TMD) software and analyze the data accuracy of the TPXO 7.1 model. The research method to process tidal observation data is using the admiralty method and tidal prediction data obtained from the TPXO 7.1 model. The calculation of Root Mean Square Error (RMSE) and correlation coefficient have been done. The research was conducted in March 2018. Generally, the results show a significant correlation between observation data and TPXO 7.1 model prediction product which both data have mixed tide type prevailing Semidiurnal. The RMSE and correlation coefficient are 0.14 and 0.73, thus the TPXO 7.1 model can be used to obtain tide data in the unmeasured area.

Keywords: tidal, Model TPXO 7.1, tidal prediction, tidal type.

Analisis Pemodelan Data Pasang Surut Menggunakan Model Tpxo 7.1 di Pelabuhan Tanjung Priok, Jakarta Utara - Septi Hermialingga, Anna IS Purwiyanto, \& Iskhaq Iskandar 


\section{PENDAHULUAN}

Hardjono (2016) Pelabuhan Tanjung Priok berada di perairan teluk Jakarta Utara yang berfungsi sebagai tempat keluar-masuk kegiatan perdagangan eksporimpor antar pulau yang dikelola PT. Pelabuhan Indonesia II. Pelabuhan Tanjung Priok memiliki aktifitas pembangunan dan pelayaran yang tinggi oleh karena itu sangat dibutuhkan informasi mengenai ketinggian pasang surut guna mendukung perencanaan pembangunan pelabuhan, perencanaan alur keluar masuk kapal untuk bongkar muat barang di pelabuhan serta kepentingan keselamatan pelayaran.

Pasang surut merupakan fenomena naik turunnya permukaan air laut secara periodik. Hal ini diakibatkan oleh kombinasi gaya gravitasi dan gaya tarik menarik dari benda-benda astronomi terutama oleh matahari, bumi, dan bulan. Pengaruh benda astronomi lainnya dapat diabaikan karena jaraknya yang lebih jauh atau ukurannya lebih kecil (Sangkop et al., 2015). Perencanaan pelayaran dan pembangunan perlu mengetahui elevasi muka air tertinggi (pasang) dan terendah (surut) perairan (Astari et al., 2018).

Pengukuran pasang surut di Pelabuhan Tanjung Priok saat ini menggunakan alat automatic gauge yang terletak di kolam ke-3 pada Pelabuhan. Seiring berjalannya waktu tentunya pada alat ini dapat mengalami kerusakan alat, maupun penurunan kinerja perekaman dan sebagainya. Maka dari itu, diperlukan alternatif untuk mendapatkan data pasang surut. Salah satu alternatif untuk mendapatkan data pasang surut di suatu lokasi yaitu menggunakan prediksi pasang surut Model TPXO 7.1 yang dapat dijalankan dengan perangkat lunak Tidal Model Driver (TMD). Model pasut Tidal Model Driver (TMD) dapat mengekstraksi konstanta harmonik dan prediksi elevasi pasut pada lokasi dan waktu yang diberikan secara global. Ekstraksi serta prediksi konstanta pasut model TPXO 7.1 melibatkan 11 konstituen pasut yaitu M2, K1, K2, N2, O1, P1, Q1, S2, MM, MF dan M4 (Padman, 2005). Model pasut TPXO 7.1 menggunakan satelit altimetri TOPEX/Poseidon. Sistem kerja satelit altimetri dapat diuraikan sebagai berikut : altimeter mengirimkan sinyal elektromagnetik ke permukaan perairan, kemudian sinyal elektromagnetik terpantulkan kembali dari permukaan perairan dan diterima oleh altimeter (Safi'i et al., 2018). Penentuan jarak antara satelit dengan permukaan perairan dapat diukur dari waktu yang ditempuh sinyal elektromagnetik untuk kembali ke satelit (Handoko et al., 2018). Menurut Piccioni et al. (2018) Satelit altimetri mampu menyediakan data dengan tingkat akurasi dalam satuan sentimeter untuk daerah laut dalam dan akurasinya dapat sangat bervariasi di daerah perairan dangkal/paparan dan pantai dengan nilai maksimum perbedaan sebesar 1 meter (Umam, 2013). Satelit T/P didesain khusus untuk mengamati dan memahami dinamika laut (sirkulasi laut, pasut, dan lain-lain) dengan interval sampling 10 hari atau 237,975 jam karena data T/P mencakup pengamatan seluruh perairan Indonesia dan juga global.

Tujuan dari penelitian ini yaitu membandingkan karakteristik pasang surut observasi dengan karakteristik pasang surut prediksi model TPXO 7.1 dari perangkat lunak Tidal Model Driver (TMD) serta menganalisa keakurasian data pasang surut model TPXO 7.1.

\section{BAHAN DAN METODE}

Penelitian dilakukan pada Maret 2018 menggunakan data lapangan selama 29 hari pengamatan dengan titik koordinat lokasi alat automatic gauge yaitu $6^{\circ} 6^{\prime} 24$ " LS dan $106^{\circ}$ 53' 26" BT pada kolam ke-3 PT Pelabuhan Indonesia II Tanjung Priok, Jakarta Utara. Peta lokasi dapat dilihat pada Gambar 1.

Pengumpulan data prediksi pasang surut diperoleh dari software Tidal Model Driver (TMD) dan data observasi pasang surut didapat dari alat pengukur pasang surut di Pelabuhan Tanjung Priok. Selanjutnya dilakukan validasi data pasang surut hasil model dengan data observasi menggunakan perhitungan Root Mean Square Error dan korelasi dari kedua data.

Data observasi diolah menggunakan metode admiralty karena metode ini tidak hanya mempertimbangkan faktor astronomis tetapi juga mempertimbangkan faktor meteorologis pada suatu lokasi sehingga dapat melihat variasi pasut yang terjadi berdasarkan bulanan dan musiman. Metode ini membutuhkan ketelitian lebih dalam pengolahannya, tidak dapat digunakan untuk data-data panjang (> 29 hari), dan hanya menghasilkan sembilan komponen pasang surut. Proses perhitungan analisa harmonik metode Admiralty dilakukan pengembangan perhitungan sistem formula dengan bantuan perangkat lunak Excel yang akan menghasilkan harga beberapa parameter yang ditabelkan sehingga perhitungan pada metode ini akan menjadi efisien dan memiliki keakuratan yang tinggi serta fleksibel untuk waktu kapanpun (Korto, Jasin, \& Mamoto, 2015).

Root Mean Square Error (RMSE) digunakan untuk menghitung jumlah dari selisih data yang sebenarnya 


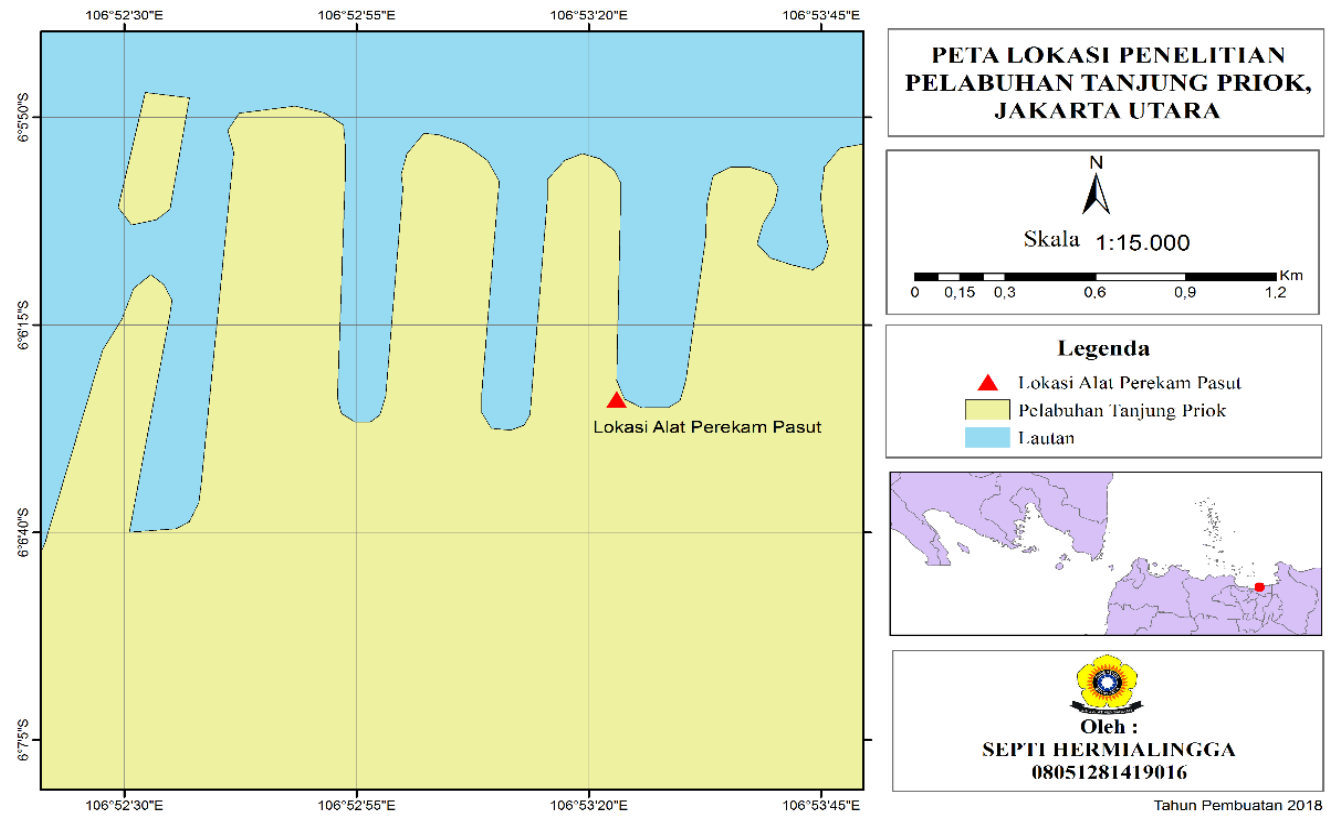

Gambar 1. Peta Lokasi Penelitian.

Figure 1. Research Location Map.

dengan data peramalan dibagi jumlah seluruh data. Umumnya, ramalan data akan semakin akurat apabila nilai MSE semakin kecil. Menurut Atmodjo (2011) dalam Candrasari et al. (2015) Verifikasi suatu model dapat diterima kebenarannya apabila nilai MSE masih berada didalam ambang batas $40 \%$. Hasil data lapangan kemudian dibandingkan dengan data hasil model menggunakan persamaan Root Mean Square Error (RMSE).

$R M S E=\sqrt{\frac{\sum_{i=1}^{n}(\text { Xobs. } i-\text { Xmodel. } i)^{2}}{n}}$

Menurut Sarwono (2006) koefisien korelasi adalah pengukuran statistik kovarian atau asosiasi antara dua variabel. Kriteria hubungan antara dua variabel dapat dikategorikan sebagai berikut :

$\mathrm{R}=0 \quad$ :Tidak ada korelasi antara dua variabel $0<\mathrm{R}=0,20 \quad$ : Korelasi data tidak bisa dipercaya $0,20<\mathrm{R}=0,40$ : Korelasi data kurang bisa dipercaya $0,40<\mathrm{R}=0,70$ : Korelasi cukup berarti data cukup dipercaya

$0,70<\mathrm{R}=0,90$ : Korelasi tinggi data dapat dipercaya $0,90<\mathrm{R}=1,00$ : Korelasi sangat tinggi data sangat bisa dipercaya

Rumus untuk persaman korelasi koefisien adalah sebagai berikut (Goel, 2011):

$$
R=\frac{\sum x y}{\sqrt{\sum x^{2} \sum y^{2}}}
$$

\section{HASIL DAN PEMBAHASAN}

Perbandingan elevasi data pasang surut hasil pengamatan observasi dengan pasang surut prediksi pelabuhan Tanjung Priok divisualisasikan dalam bentuk grafik sehingga akan terlihat perbandingan naik turun elevasi dari kedua data terhadap waktu yang dapat dilihat pada Gambar 2.

Secara umum perbedaan ketinggian elevasi pasang surut data prediksi yang mengalami overestimate (menaksir terlalu tinggi) dimana amplitudo pasang surut prediksi dominan lebih besar dibanding data observasi, terutama amplitudo prediksi saat transisi dari pasang perbani menuju pasang purnama. Menurut Tarakanov et al. (2018) Selisih amplitudo ini diduga karena resolusi model TPXO 7.1 itu sendiri yaitu 1/4 derajat grid global sehingga tidak dapat merepresentasikan kondisi perairan di titik observasi secara detail dan karena resolusi waktu dari satelit Topex/Poseidon yang mengulangi jalur darat yang sama setiap 10 hari oleh karena itu data pasut yang terjadi pada rentang waktu 10 hari tersebut tidak dapat terekam sehingga mengakibatkan data terinterpolasi.

Data observasi memiliki pola amplitudo yang lebih 


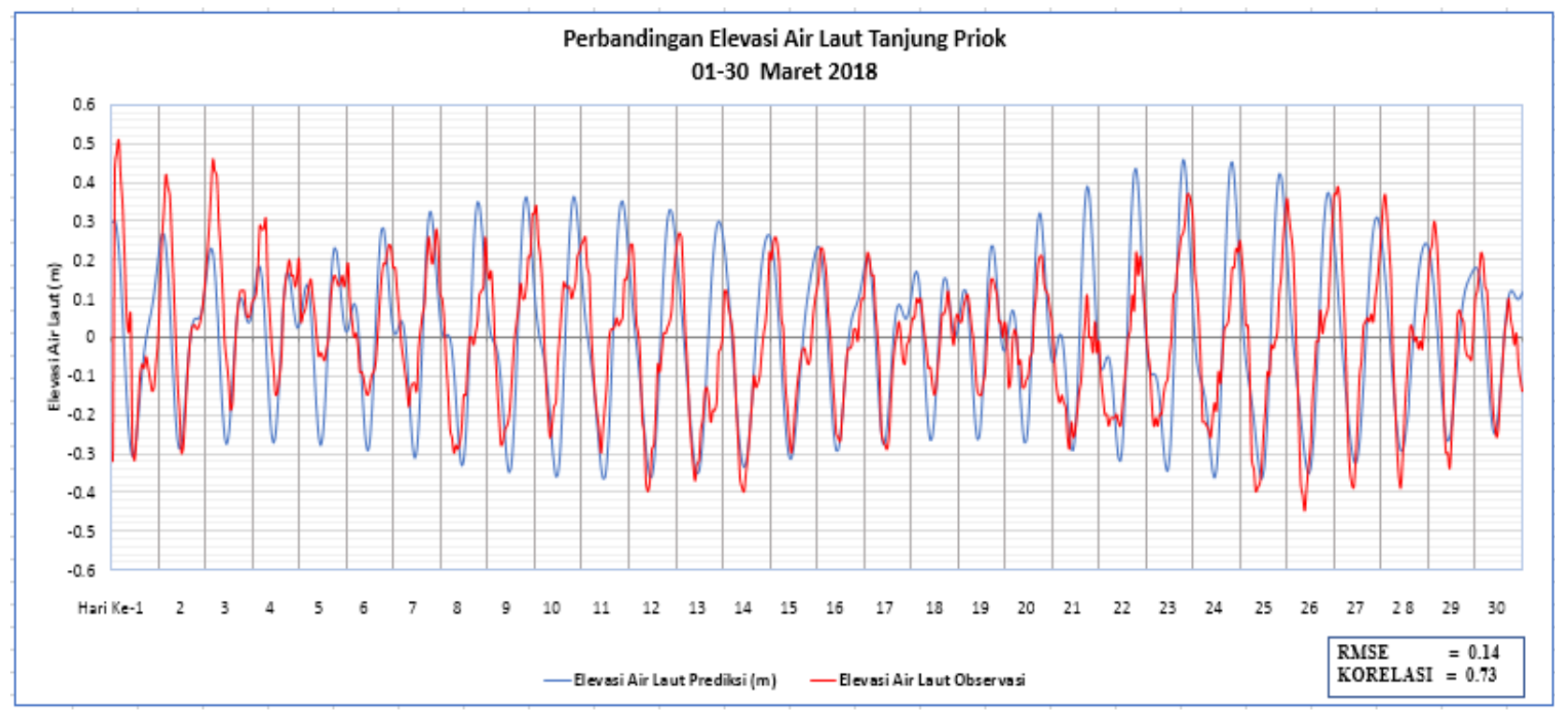

Gambar 2. Grafik Perbandingan Elevasi Air Laut.

Figure 2. Comparison Chart of Sea Water Elevation.

bervariasi dibandingkan dengan data prediksi. Hal ini dapat disebabkan karena data observasi yang diteliti nilai ketinggiannya didapatkan secara langsung sesuai dengan kondisi lapangan dan ada juga faktor lain seperti adanya gelombang dari pengaruh alam atau aktifitas perkapalan, tidak tepatnya bacaan tinggi permukaan air laut yang terekam, terjadi kerusakan alat. Hasil nilai formzahl kedua data tersebut mempunyai nilai $1,5<\mathrm{F} \leq 3$ sehingga dapat diklasifikasikan sebagai tipe pasang surut campuran dominan ke tunggal (mixed tide prevailing diurnal) (Suhaemi et al., 2018).

Tingkat kesalahan pada penelitian ini memiliki nilai Root Mean Square Error (RMSE) sebesar 0,14. Hal ini berarti menunjukkan verifikasi model dan nilai MSE dapat diterima kebenarannya karena masih berada didalam ambang batas 40\% (Candrasari et al., 2015). Selanjutnya dilihat korelasi dari kedua data pasang surut observasi dan prediksi, perbandingan elevasi air laut Tanjung Priok memiliki nilai korelasi sebesar 0,73 . Berdasarkan kriteria korelasi yang dikemukakan Sarwono (2006) nilai korelasi berada pada range 0,70 $<\mathrm{R}=0,90$ yang berarti bahwa nilai korelasi tinggi dan data dapat dipercaya. Dengan demikian perbandingan data observasi dengan data prediksi Model TPXO 7.1 memiliki tingkat error yang kecil dan memiliki hubungan yang tinggi sehingga data dapat dipercaya. Selain itu juga terdapat level of significance (tingkat kepercayaan) pada data adalah $99 \%$.

Data perbandingan nilai amplitudo komponen harmonik pasang surut ditunjukkan pada Gambar 3 dimana komponen pasang surut $\mathrm{K} 1$ dan $\mathrm{O} 1$ memiliki nilai amplitudo yang lebih dominan berpengaruh terhadap pasang surut dibandingkan komponen yang lain baik pada data observasi maupun prediksi. Nilai kelambatan fase dapat dilihat pada Gambar 4. Nilai kelambatan fase di perairan Tanjung Priok dapat disebabkan karena Laut Jawa memiliki perbedaan topografi dasar laut dimana perairan Tanjung Priok yang termasuk dalam bagian Barat Laut Jawa pasutnya berasal dari Lautan Pasifik yang merambat melalui Laut Cina Selatan dan melewati daerah dangkal sebelum memasuki Laut Jawa (Ongkosongo \& Suyarso, 1989).

Data pengamatan observasi dengan prediksi pasut di lokasi pelabuhan Tanjung Priok terdapat selisih nilai beda fase (konstanta sudut pada sebuah gerakan) yang cukup besar. Namun nilai selisih beda fase yang cukup besar dibeberapa komponen tersebut tidak terlalu signifikan mempengaruhi hasil prediksi karena muncul pada komponen pasang surut yang fasenya tidak dominan.

\section{KESIMPULAN DAN SARAN}

Hasil yang didapatkan dari penelitian melalui pengolahan dan analisis data, maka dapat disimpulkan sebagai berikut :

1. Karakteristik pasut di perairan Pelabuhan Tanjung Priok dari data prediksi model TPXO 7.1 dan data pengamatan langsung sama-sama memiliki tipe pasang surut campuran dominan ke tunggal.

2. Akurasi data pasang surut model TPXO 7.1 


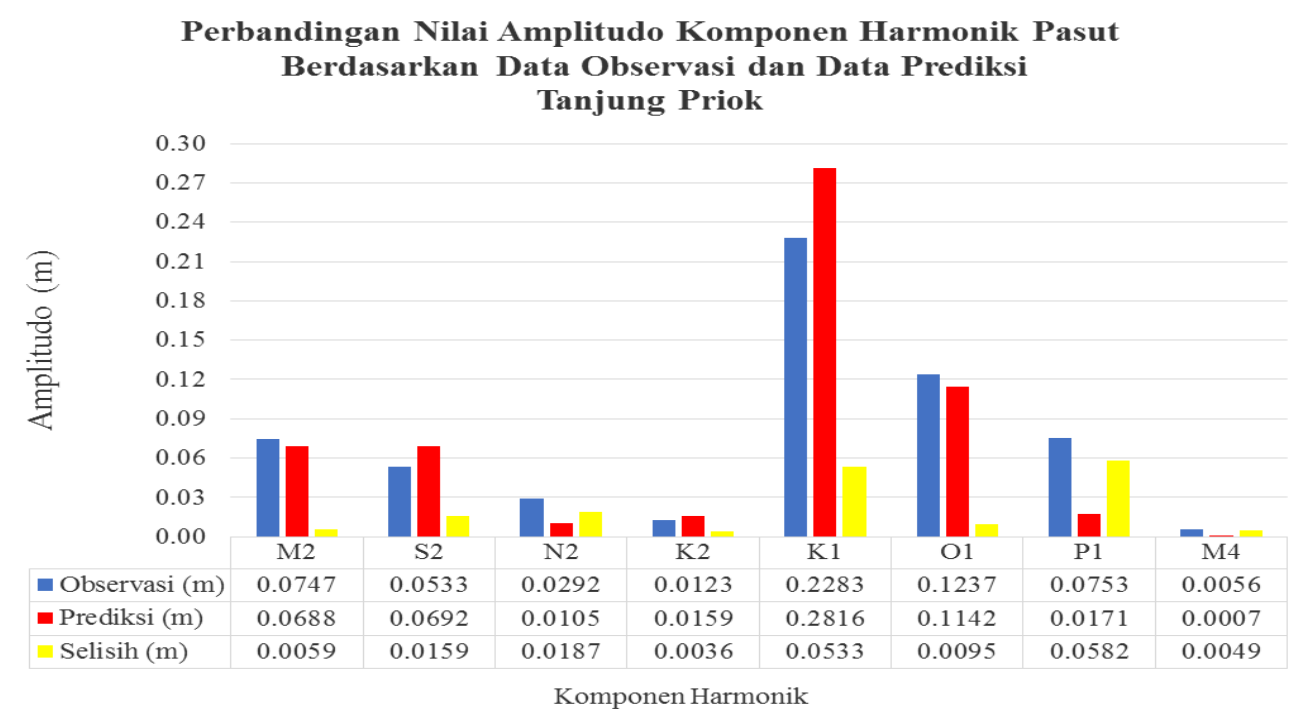

Gambar 3. Perbandingan Nilai Amplitudo Data Observasi dan Prediksi Komponen Harmonik Pasut Tanjung Priok. Figure 3. Comparison of Amplitude Values Observation Data and Prediction of Tanjung Priok's Harmonic Components.

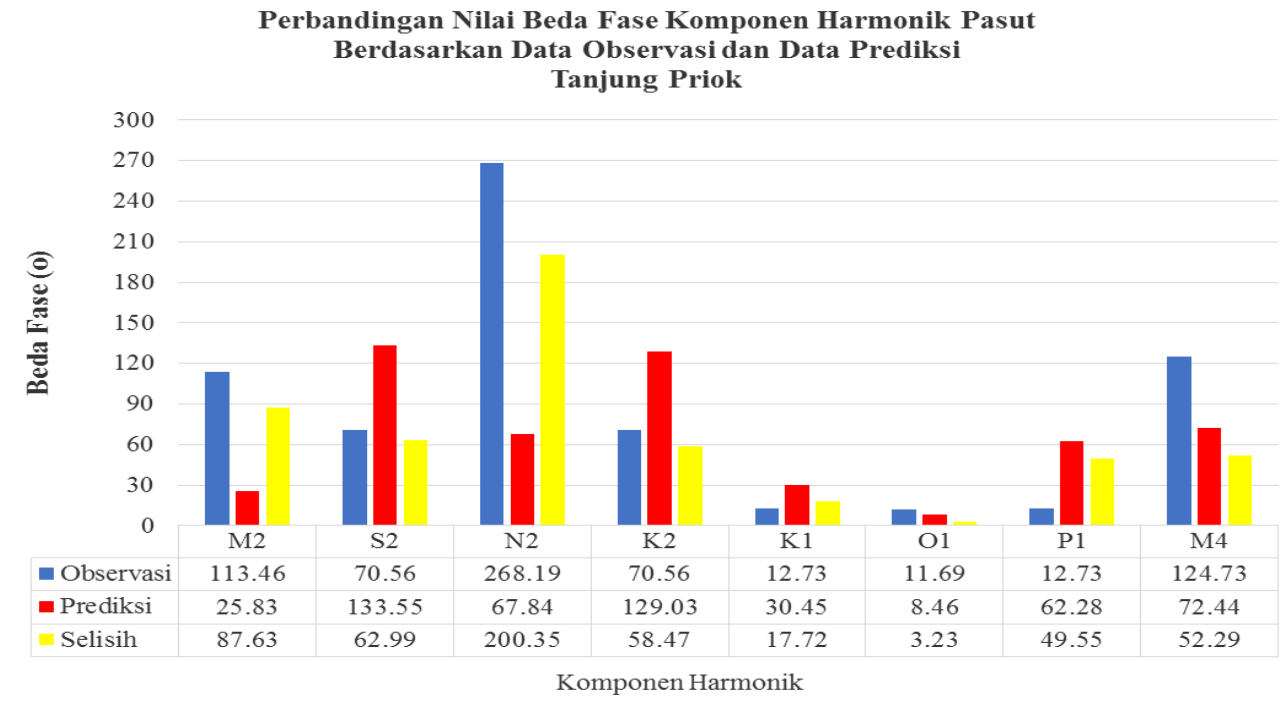

Gambar 3. Perbandingan Nilai Beda Fase Data Observasi dan Prediksi Komponen Harmonik Pasut Tanjung Priok. Figure 3. Comparison of the Value of Different Phases of Observation and Prediction of Tanjung Priok's Harmonic Components.

memiliki tingkat error yang kecil (RMS error sebesar 0,14) dan memiliki hubungan yang tinggi (korelasi sebesar 0,73) sehingga data dapat dipercaya.

Hasil penelitian ini menunjukkan bahwa hasil Tidal Model Driver (TMD) model TPXO 7.1 memiliki amplitudo yang relatif lebih besar dari amplitudo data hasil observasi. Hal ini diduga disebabkan karena resolusi model TPXO 7.1 tidak dapat menggambarkan secara detil lokasi pengamatan. Oleh karena itu, perlu dilakukan kajian dan perbandingan dengan data hasil observasi di perairan terbuka. Penulis menyarankan untuk melakukan kajian pada stasiun pengamatan pasang surut di Pulau Christmas, Australia dan di Pulau Gan, Maldives. Kedua stasiun tersebut berada di perairan terbuka Samudera Hindia.

\section{UCAPAN TERIMA KASIH}

Ucapan terima kasih penulis kepada pihak PT Pelabuhan Indonesia II, Tanjung Priok sebagai tempat penelitian dan Bayu Triyogo Widyantoro di Badan 
Informasi Geospasial atas dukungan data pasang surut yang diberikan sehingga paper ini dapat terselesaikan dengan baik. Penulis juga mengucapkan terimakasih kepada Pembimbing Anna IS Purwiyanto, M.Si dan Prof. Dr. Iskhaq Iskandar Fakultas Matematika dan Ilmu Pengetahuan Alam, Universitas Sriwijaya.

\section{DAFTAR PUSTAKA}

Astari, K. F., Hendri, A., \& Fauzi, M. (2018). Analisis Pasang Surut Perairan Dumai Menggunakan Metode Admiralty. Jom FTEKNIK, 5.

Candrasari, K., Rifai, A., \& Handoyo, G. (2015). Peramalan Nilai MSL Berdasarkan Data Pasang Surut Dengan Metode Admiralty Dan Autoregressive Integrated Moving Average (ARIMA) Di Perairan Pulau Pari Kepulauan Seribu. Jurnal Oseanografi, 4(1).

Goel, A. (2011). ANN-Based Approach for Predicting Rating Curve of an Indian River. Civil Engineering, 4 hal.

Handoko, E. Y., Yuwono, Ariani, R., \& Filaili, R. B. (2018). Korelasi Multivariate El Nino Southern Oscillator Index Dan Variasi Permukaan Laut Di Perairan Indonesia. Geoid, 14(1).

Hardjono, S. (2016). Analisa Daya Mesin dan Bollard Pull Kapal Tunda Untuk Kapal Peti Kemas Post-Panamax Di Pelabuhan Kalibaru. Warta Penelitian Perhubungan, 28(3).

Korto, J., Jasin, M. I., \& Mamoto, J. D. (2015). Analisis Pasang Surut Di Pantai Nuangan (Desa Iyok) Boltim Dengan Metode Admiralty. JURNAL SIPIL STATIK, 3(6), 391-402.

Ongkosongo, O., \& Suyarso. (1989). Pasang Surut. Jakarta: Pusat Penelitian dan Pengembangan Oseanologi (P3O LIPI).

Padman, L. (2005). Tide Model Driver (TMD) Manual. USA. Earth and Space Research.

Piccioni, G., Dettmering, D., Passaro, M., Bosch, W., \& Seitz, F. (2018). Coastal Improvements for Tide Models: The Impact of ALES Retracker. Remote Sensing, 10.

Safi'i,A.N., Syetiawan,A., Kusuma, H.A., Lumbangaol, Y. A., Rudiastuti, A. W., \& Oktaviani, N. (2018).
Optimalisasi Data Satelit Altimetri Untuk Menghitung Konstanta Harmonik Pasang Surut. Cibinong: Badan Informasi Geospasial.

Sangkop, N., Mamoto, J. D., \& Jasin, M. I. (2015). Analisis Pasang Surut Di Pantai Bulo Desa Rerer Kecamatan Kombi Kabupaten Minahasa Dengan Metode Admiralty. TEKNO, 13(63), 60-69.

Sarwono, J. (2006). Metode Penelitian Kuantitatif dan Kualitatif. Yogyakarta: Graha Ilmu.

Suhaemi, Raharjo, S., \& Marhan. (2018). Penentuan Tipe Pasang Surut Perairan Pada Alur Pelayaran Manokwari Dengan Menggunakan Metode Admiralty. Jurnal Sumberdaya Akuatik Indopasifik, 2(1).

Tarakanov, R. Y., Morozov, E. G., Haren, H. v., Makarenko, N. I., \& Demidova, T. A. (2018). Structure of the Deep Spillway in the Western Part of the Romanche Fracture Zone. American Geophysical Union.

Umam, R. K. (2013). Pemodelan Pasang Surut Perairan Pulau Jawa Menggunakan Perangkat Lunak Tidal Model Driver Dan Model Pasut Global TPXO 7.1. Fakultas Teknik Universitas Gadjah Mada.

JURNAL KELAUTAN NASIONAL, Vol. 15, No 2, Agustus 2020, Hal. 85-90 